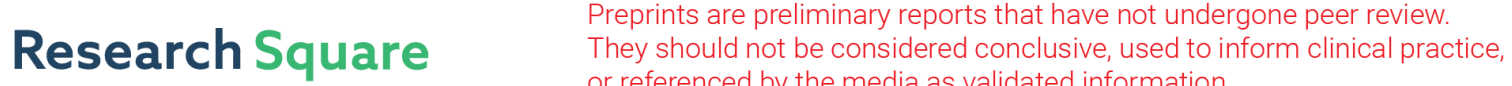 or referenced by the media as validated information. \\ Determination Morse Potential Parameters by the Theoretical Method in EXAFS
}

Nguyen Ba Duc ( $\nabla$ ducnb@daihoctantrao.edu.vn )

Tan Trao University

\section{Trinh Phi Hiep}

Tan Trao University

\section{Nguyen Thu}

Hanoi Pedagogical University 2

\section{Research Article}

Keywords: Morse potential parameter, state equation, correlation function, elastic constant, mean square relative displacement

Posted Date: February 18th, 2021

DOl: https://doi.org/10.21203/rs.3.rs-208602/v1

License: (c) (i) This work is licensed under a Creative Commons Attribution 4.0 International License. Read Full License 


\title{
Determination Morse potential parameters by the theoretical method in EXAFS
}

\author{
Nguyen Ba Duc ${ }^{1, *}$, Trinh Phi Hiep ${ }^{1}$, Nguyen Van Thu ${ }^{2}$ \\ ${ }^{1}$ Tan Trao University, Tuyen Quang, Viet Nam; ${ }^{2}$ Hanoi Pedagogical University 2 \\ * Email: ducnb@daihoctantrao.edu.vn
}

\begin{abstract}
A new method for estimating Morse potential's effective parameters has developed using the sublimation energy, the compressibility, and the lattice constant in expanded X-ray absorption fine structure spectra. Application the received parameters of Morse potential to calculate the mean square relative displacement, elastic constant, anharmonic effective potential, correlated function, and local force constant for diamond-type structure crystals such as silicon and germanium crystals, and face-centered cubic crystals as copper, silver. Numerical results agree well with the experimental values and other theories.
\end{abstract}

Keywords: Morse potential parameter; state equation; correlation function; elastic constant; mean square relative displacement.

\section{Introduction}

In Expanded X-ray Absorption Fine Structure (EXAFS) spectra with the anharmonic effects, the anharmonic Morse potential [1] is suitable for describing the interaction and oscillations of atoms in the crystals [2-7]. In the EXAFS theory, photoelectrons are emitted by the absorber scattered by surrounded vibrating atoms [1,2]. This thermal oscillation of atoms contributes to the EXAFS spectra, especially the anharmonic EXAFS [2-7], which is affected by these spectra's physical information. In the EXAFS spectrum analysis, the parameters of Morse potential is usually extracted from the experiment. Still, experimental data are not available in many cases, so a theory is necessary to deduce Morse potential parameters. The only calculation has been carried out for cubic crystals [8]. The results have been used actively for calculations EXAFS thermodynamic parameters [6] and reasonable with those extracted from EXAFS data [9] using anharmonic correlated Einstein model [8]. Therefore, the requirement for calculation of the anharmonic Morse interaction potential due to thermal disorder for other structures is essential.

The purpose of this study is to expand a method for calculating the Morse potential parameters using the energy of sublimation, the compressibility, and the lattice constant with the effect of the disorder of temperature. Use the Morse potential parameters received to calculate the mean square relative displacement (MSRD), mean square displacement (MSD), elastic constant, anharmonic interatomic effective potential, and effective local force constant for diamond-type (DIA) structure crystals such as silicium ( $\mathrm{Si}$ ), germanium $(\mathrm{Ge}), \mathrm{SiGe}$ semiconductor, and face-centered cubic (fcc) crystals as copper $(\mathrm{Cu})$, silver $(\mathrm{Ag})$ and $\mathrm{CuAg}$ alloy. Numerical results are suitable for the experimental values and other theories [10], [11], [17-20]. 


\section{Formalism}

The $\varepsilon\left(r_{i j}\right)$ potential of atoms $i$ and $j$ separated by a distance $r_{i j}$ is given in by the Morse function:

$$
\varepsilon\left(\mathrm{r}_{\mathrm{ij}}\right)=\mathrm{D}\left\{\mathrm{e}^{-2 \alpha\left(\mathrm{r}_{\mathrm{ij}}-\mathrm{r}_{\mathrm{o}}\right)}-2 \mathrm{e}^{-\alpha\left(\mathrm{r}_{\mathrm{ij}}-\mathrm{r}_{\mathrm{o}}\right)}\right\},
$$

where $1 / \alpha$ describes the width of the potential, $\mathrm{D}$ is the dissociation energy $\left(\varepsilon\left(\mathrm{r}_{0}\right)=-\mathrm{D}\right)$; $\mathrm{r}_{0}$ is the equilibrium distance of the two atoms.

To obtain the potential energy of a large crystal whose atoms are at rest, it is necessary to sum Eq. (1) over the entire crystal. It is quickly done by selecting an atom in the lattice as origin, calculating its interaction with all others in the crystal, and then multiplying by $\mathrm{N} / 2$, where $\mathrm{N}$ is the total number of atoms in a crystal. Therefore, the potential $\mathrm{E}$ is given by:

$$
\mathrm{E}=\frac{1}{2} \mathrm{ND} \sum_{\mathrm{j}}\left\{\mathrm{e}^{-2 \alpha\left(\mathrm{r}_{\mathrm{j}}-\mathrm{r}_{\mathrm{o}}\right)}-2 \mathrm{e}^{-\alpha\left(\mathrm{r}_{\mathrm{j}}-\mathrm{r}_{\mathrm{o}}\right)}\right\} \text {. }
$$

Here $r_{j}$ is the distance from the origin atom to the jth atom. It is beneficial to describe the following quantities:

$$
r_{j}=\left[m_{j}^{2}+n_{j}^{2}+1_{j}^{2}\right]^{1 / 2} a=M_{j} a,
$$

where $m_{j}, n_{j}, l_{j}$ are position coordinates of atoms in the lattice. Substitute the Eq. (3) into Eq. (2), the potential energy can be rewritten as:

$$
\mathrm{E}(\mathrm{a})=\frac{1}{2} \mathrm{NDe}^{\alpha \mathrm{r}_{0}}\left[\mathrm{e}^{\alpha \mathrm{x}_{0}} \sum_{\mathrm{j}} \mathrm{e}^{-2 \alpha \mathrm{aM}} \mathrm{j}-2 \sum_{\mathrm{j}} \mathrm{e}^{-\alpha \mathrm{aM}} \mathrm{j}\right]
$$

The first and second derivatives of the potential energy of Eq. (4) concerning a, we have:

$$
\begin{aligned}
& \frac{d E}{d a}=-\alpha N D e^{\alpha r_{0}}\left[e^{\alpha r_{0}} \sum_{j} M_{j} e^{-2 \alpha a M_{j}}+\sum_{j} M_{j} e^{-\alpha a M_{j}}\right], \\
& \frac{d^{2} E}{d a^{2}}=\alpha^{2} N^{\alpha r_{0}}\left[2 e^{\alpha r_{0}} \sum_{j} M_{j}^{2} e^{-2 \alpha a M_{j}}-\sum_{j} M_{j}^{2} e^{-\alpha a M_{j}}\right] .
\end{aligned}
$$

At absolute zero $\mathrm{T}=0, \mathrm{a}_{0}$ is the value of $\mathrm{a}$ for which the lattice is in equilibrium, then $\mathrm{E}\left(\mathrm{a}_{0}\right)$ gives the energy of cohesion, $\left[\frac{\mathrm{dE}}{\mathrm{da}}\right]_{\mathrm{a}_{0}}=0$, and $\left[\frac{\mathrm{d}^{2} \mathrm{E}}{\mathrm{da}^{2}}\right]_{\mathrm{a}_{0}}$ is related to the compressibility [10]. That is,

$$
\mathrm{dE}\left(\mathrm{a}_{0}\right)=\mathrm{E}_{0}\left(\mathrm{a}_{0}\right)
$$

where $\mathrm{E}_{0}\left(\mathrm{a}_{0}\right)$ is the energy of sublimation at zero pressure and temperature,

$$
\left(\frac{\mathrm{dE}}{\mathrm{da}}\right)_{\mathrm{a}_{0}}=0
$$

and the compressibility is given by [8] 


$$
\frac{1}{\kappa_{0}}=\mathrm{V}_{0}\left(\frac{\mathrm{d}^{2} \mathrm{E}_{0}}{\mathrm{dV}^{2}}\right)_{\mathrm{a}_{0}}=\mathrm{V}_{0}\left(\frac{\mathrm{d}^{2} \mathrm{E}}{\mathrm{dV}^{2}}\right)_{\mathrm{a}_{0}},
$$

where $\mathrm{V}_{0}$ is the volume at $\mathrm{T}=0$ and $\kappa_{0}$ is compressibility at zero temperature and pressure. The volume per atom N/V is related to the lattice constant a by

$$
\frac{\mathrm{V}}{\mathrm{N}}=\mathrm{ca}^{3} \text {. }
$$

Substituting Eq. (10) into Eq. (9) the compressibility is formulated by

$$
\frac{1}{\kappa_{0}}=\frac{1}{9 \mathrm{cNa}_{0}}\left(\frac{\mathrm{d}^{2} \mathrm{E}}{\mathrm{da}^{2}}\right)_{\mathrm{a}=\mathrm{a}_{0}} \text {. }
$$

Using Eq. (5) to solve Eq. (8) we obtain

$$
\mathrm{e}^{\alpha \mathrm{r}_{0}}=\frac{\sum_{\mathrm{j}} \mathrm{M}_{\mathrm{j}} \mathrm{e}^{-\alpha \mathrm{a} \mathrm{M}_{\mathrm{j}}}}{\sum_{\mathrm{j}} \mathrm{M}_{\mathrm{j}} \mathrm{e}^{-2 \alpha \mathrm{a}_{\mathrm{j}}}} .
$$

From Eqs. $(4,6,7,11)$ we derive the relation

$$
\frac{\mathrm{e}^{\alpha \mathrm{r}_{0}} \sum_{\mathrm{j}} \mathrm{e}^{-2 \alpha \mathrm{a} \mathrm{M}_{\mathrm{j}}}-2 \sum_{\mathrm{j}} \mathrm{e}^{-\alpha \mathrm{a} \mathrm{M}_{\mathrm{j}}}}{4 \alpha^{2} \mathrm{e}^{\alpha \mathrm{r}_{0}} \sum_{\mathrm{j}} \mathrm{M}_{\mathrm{j}}^{2} \mathrm{e}^{-2 \alpha \mathrm{a} \mathrm{M}_{\mathrm{j}}}-2 \alpha^{2} \sum_{\mathrm{j}} \mathrm{M}_{\mathrm{j}}^{2} \mathrm{e}^{-\alpha \mathrm{a} \mathrm{M}_{\mathrm{j}}}}=\frac{\mathrm{E}_{0} \kappa_{0}}{9 \mathrm{cNa} \mathrm{N}_{0}} .
$$

Solving the system of Eq. $(12,13)$ we obtain $\alpha$ and $r_{0}$. Using $\alpha$ and Eq. (4) to solve Eq. (7) we receive $\mathrm{D}$. The Morse potential parameters $\mathrm{D}, \alpha$ depends on the compressibility $\kappa_{0}$, the energy of sublimation $\mathrm{E}_{0}$ and the lattice constant a. These values of all crystals are available already [12].

Next, we apply the above expressions to claculate the equation of state and elastic constants. It is possible to calculate the state equation from the potential energy E. If we assumed that the Debye model could express the thermal section of the free energy, then the Helmholtz energy is given by [8]

$$
\begin{gathered}
\mathrm{F}=\mathrm{E}+3 \mathrm{Nk}_{\mathrm{B}} \mathrm{T} \ln \left(1-\mathrm{e}^{-\theta_{\mathrm{D}} / \mathrm{T}}\right)-\mathrm{Nk}_{\mathrm{B}} \mathrm{TD}\left(\theta_{\mathrm{D}} / \mathrm{T}\right) \\
\mathrm{D}\left(\frac{\theta_{\mathrm{D}}}{\mathrm{T}}\right)=3\left(\frac{\mathrm{T}}{\theta_{\mathrm{D}}}\right)^{3} \int_{0}^{\theta_{\mathrm{D}} / \mathrm{T}} \frac{\mathrm{x}^{3}}{\mathrm{e}^{\mathrm{x}}-1} \mathrm{dx}
\end{gathered}
$$

where $\mathrm{k}_{\mathrm{B}}$ is Boltzmann constant, $\theta_{\mathrm{D}}$ is Debye temperature.

Using Eqs. $(14,15)$ we derive the equation of state as

$$
\mathrm{P}=-\left(\frac{\partial \mathrm{F}}{\partial \mathrm{V}}\right)_{\mathrm{T}}=\frac{1}{3 \mathrm{ca}^{2}} \frac{\mathrm{dE}}{\mathrm{da}}+\frac{3 \gamma_{\mathrm{G}} \mathrm{RT}}{\mathrm{V}} \mathrm{D}\left(\frac{\theta_{\mathrm{D}}}{\mathrm{T}}\right),
$$

where $\gamma_{G}$ is the Grüneisen parameter, $\mathrm{V}$ is the volume. 
After transformations, the Eq. (16) is resulted as

$$
\begin{gathered}
\mathrm{P}=\frac{\left[\mathrm{NDe}^{\alpha \mathrm{r}_{0}} \alpha \sum_{\mathrm{j}} \mathrm{M}_{\mathrm{j}} \mathrm{e}^{-\alpha \mathrm{a}_{0} \mathrm{M}_{\mathrm{j}}(1-\mathrm{x})^{1 / 3}}\right]}{3 c \mathrm{a}_{0}^{2}(1-\mathrm{x})^{2 / 3}}-\mathrm{NDe}^{2 \alpha \mathrm{r}_{0}} \alpha \sum_{\mathrm{j}} \mathrm{M}_{\mathrm{j}} \mathrm{e}^{-2 \alpha \mathrm{a}_{0} \mathrm{M}_{\mathrm{j}}(1-\mathrm{x})^{1 / 3}}+\frac{3 \gamma_{\mathrm{G}} \mathrm{RT}}{\mathrm{V}_{0}(1-\mathrm{x})} \mathrm{D}\left(\frac{\theta_{\mathrm{D}}}{\mathrm{T}}\right), \\
\mathrm{x}=\frac{\mathrm{V}_{0}-\mathrm{V}}{\mathrm{V}_{0}}, \quad \mathrm{~V}_{0}=\mathrm{ca}_{0}^{3}, \mathrm{R}=\mathrm{Nk}_{\mathrm{B}}, \mathrm{N}=6.02 \times 10^{23} .
\end{gathered}
$$

The equation of state (17) contains the obtained Morse potential parameters, $\mathrm{c}$ is a constant and has value according to the structure of the crystal.

Elastic properties of a crystal described by an elastic tensor contained in the motion equation of the crystal. The non-vanishing elements of the elastic tensor defined as elastic constants. They are given for lattice structure crystals by [13]

$$
\begin{gathered}
\mathrm{c}_{11}=\mathrm{c}_{22}=\sqrt{2} \mathrm{r}_{0}\left[10 \Psi^{\prime \prime}\left(\mathrm{r}_{0}^{2}\right)+16 \Psi^{\prime \prime}\left(2 \mathrm{r}_{0}^{2}\right)+81 \Psi^{\prime \prime}\left(3 \mathrm{r}_{0}^{2}\right) \Lambda\right]-\frac{\left\{\sqrt{\frac{2}{3}}\left[-2 \Psi^{\prime \prime}\left(\mathrm{r}_{0}^{2}\right)+16 \Psi^{\prime \prime}\left(2 \mathrm{r}_{0}^{2}\right)-40 \Psi^{\prime \prime}\left(3 \mathrm{r}_{0}^{2}\right) \Lambda\right]\right\}^{2}}{\sqrt{2} \mathrm{r}_{0}^{-1}\left[4 \Psi^{\prime \prime}\left(\mathrm{r}_{0}^{2}\right)+16 \Psi^{\prime \prime}\left(2 \mathrm{r}_{0}^{2}\right)+12 \mathrm{r}_{0}^{-1} \Psi^{\prime}\left(2 \mathrm{r}_{0}^{2}\right) \Lambda\right]}, \\
\mathrm{c}_{12}=\frac{\sqrt{2} \mathrm{r}_{0}\left[10 \Psi^{\prime \prime}\left(\mathrm{r}_{0}^{2}\right)+16 \Psi^{\prime \prime}\left(2 \mathrm{r}_{0}^{2}\right)+81 \Psi^{\prime \prime}\left(3 \mathrm{r}_{0}^{2}\right) \Lambda\right]}{3}+\frac{\left\{\sqrt{\frac{2}{3}}\left[-2 \Psi^{\prime \prime}\left(\mathrm{r}_{0}^{2}\right)+16 \Psi^{\prime \prime}\left(2 \mathrm{r}_{0}^{2}\right)-40 \Psi^{\prime \prime}\left(3 \mathrm{r}_{0}^{2}\right) \Lambda\right]\right\}^{2}}{\sqrt{2} \mathrm{r}_{0}^{-1}\left[4 \Psi^{\prime \prime}\left(\mathrm{r}_{0}^{2}\right)+16 \Psi^{\prime \prime}\left(2 \mathrm{r}_{0}^{2}\right)+12 \mathrm{r}_{0}^{-1} \Psi^{\prime}\left(2 \mathrm{r}_{0}^{2}\right) \Lambda\right]}, \quad(20) \\
\mathrm{c}_{33}=\frac{\sqrt{2}}{3} \mathrm{r}_{0}\left[32 \Psi^{\prime \prime}\left(\mathrm{r}_{0}^{2}\right)+32 \Psi^{\prime \prime}\left(2 \mathrm{r}_{0}^{2}\right)+\frac{512}{3} \Psi^{\prime \prime}\left(3 \mathrm{r}_{0}^{2}\right)+\Lambda\right], \\
\mathrm{c}_{13}=\mathrm{c}_{23}=\sqrt{2} \mathrm{r}_{0}\left[8 \Psi^{\prime \prime}\left(\mathrm{r}_{0}^{2}\right)+32 \Psi^{\prime \prime}\left(2 \mathrm{r}_{0}^{2}\right)+112 \Psi^{\prime \prime}\left(3 \mathrm{r}_{0}^{2}\right)+\Lambda\right], \\
\Psi^{\prime \prime}(\mathrm{r})=\mathrm{D} \alpha^{2}\left[2 \mathrm{e}^{-2 \alpha\left(\mathrm{r}-\mathrm{r}_{0}\right)}-\frac{1}{2} \mathrm{e}^{-\alpha\left(\mathrm{r}-\mathrm{r}_{0}\right)}\right] \frac{1}{\mathrm{r}^{2}}+\mathrm{D} \alpha\left[\mathrm{e}^{-2 \alpha\left(\mathrm{r}-\mathrm{r}_{0}\right)}-\mathrm{e}^{-\alpha\left(\mathrm{r}-\mathrm{r}_{0}\right)}\right] \frac{1}{2 \mathrm{r}^{3}} .
\end{gathered}
$$

Hence, the derived elastic constants contain the Morse potential parameters.

Next, apply to calculate of anharmonic interatomic effective potential and local force constant in EXAFS theory. The expression for the anharmonic EXAFS function [2] is described by

$$
\chi(\mathrm{k})=\mathrm{A}(\mathrm{k}) \frac{\exp [-2 \Re / \lambda(\mathrm{k})]}{\mathrm{k} \mathfrak{R}^{2}} \operatorname{Im}\left\{\mathrm{e}^{\mathrm{i} \varphi(\mathrm{k})} \exp \left[2 \mathrm{ik} \Re+\sum_{\mathrm{n}} \frac{(2 \mathrm{ik})^{\mathrm{n}}}{\mathrm{n} !} \sigma^{(\mathrm{n})}\right]\right\},
$$

where $\mathrm{A}(\mathrm{k})$ is scattering amplitude of atoms, $\varphi(\mathrm{K})$ is the total phase shift of photoelectron, $\mathrm{k}$ and $\lambda$ are wave number and mean free path of the photoelectron, respectively. The $\sigma^{(\mathrm{n})}$ are the cumulants, they describe asymmetric of anharmonic Morse potential, and they appear due to 
being average of the function $\mathrm{e}^{-2 \mathrm{ikr}}$, in which expanded of the asymmetric terms in a Taylor series around value $\Re=\langle\mathrm{r}\rangle$, with $\mathrm{r}$ is the instantaneous bond length between absorber and backscatter atoms at $\mathrm{T}$ temperature.

For describing anharmonic EXAFS, effective anharmonic potential [6] of the system is derived which in the current theory is expanded up to the third - order and given by

$$
\mathrm{E}_{\text {eff }}(\mathrm{x})=\frac{1}{2} \mathrm{k}_{\mathrm{eff}} \mathrm{x}^{2}+\mathrm{k}_{3 \mathrm{eff}} \mathrm{x}^{3}+\ldots+=\mathrm{E}(\mathrm{x})+\sum_{\mathrm{j}^{\mathrm{i}} \mathrm{i}} \mathrm{E}\left(\frac{\mu}{\mathrm{M}_{\mathrm{i}}} \mathrm{x} \hat{\mathrm{R}}_{12} \cdot \hat{\mathrm{R}}_{\mathrm{ij}}\right), \quad \mu=\frac{\mathrm{M}_{1} \mathrm{M}_{2}}{\mathrm{M}_{1}+\mathrm{M}_{2}} ; \hat{\mathfrak{R}}=\frac{\mathfrak{R}}{|\mathrm{R}|}
$$

Here $\mathrm{k}_{\text {eff }}$ is the effective local force constant, and $\mathrm{k}_{3 \mathrm{eff}}$ is the cubic parameter characterizing the asymmetry in the pair Morse potential, $\mathrm{x}$ is the deviation of instantaneous bond length between the two atoms from equilibrium. The correlated model defined as the oscillation of a pair of particles with $\mathrm{M}_{1}$ and $\mathrm{M}_{2}$ mass. Their vibration influenced by their neighbours atoms given by the sum in Eq. (24), where the sum $i$ is over absorber $(i=1)$ and backscatterer $(i=2)$, and the sum $j$ is over all their near neighbours, excluding the absorber and backscatterer themselves whose contributions are described by the term $\mathrm{E}(\mathrm{x})$. The advantage of this model is a calculation based on including the contributions of the nearest neighbours of absorber and backscatter atoms in EXAFS. The anharmonic interatomic effective potential Eq. (26) has the form

$$
\mathrm{E}_{\text {eff }}(\mathrm{x})=\mathrm{E}_{\mathrm{x}}(\mathrm{x})+2 \mathrm{E}_{\mathrm{x}}\left(-\frac{\mathrm{x}}{2}\right)+8 \mathrm{E}_{\mathrm{x}}\left(-\frac{\mathrm{x}}{4}\right)+8 \mathrm{E}_{\mathrm{x}}\left(\frac{\mathrm{x}}{4}\right) \text {. }
$$

Applying Morse potential given by Eq. (1) expanded up to $4^{\text {th }}$ order around its minimum point

$$
\mathrm{E}_{\mathrm{eff}}(\mathrm{x})=\mathrm{D}\left(\mathrm{e}^{-2 \alpha \mathrm{x}}-2 \mathrm{e}^{-\alpha \mathrm{x}}\right) \approx \mathrm{D}\left(-1+\alpha^{2} \mathrm{x}^{2}-\alpha^{3} \mathrm{x}^{3}+\frac{7}{12} \alpha^{4} \mathrm{x}^{4} \ldots\right)
$$

From Eqs. (26)-(28), we obtain the anharmonic effective potential $E_{\text {eff, effective local force }}$ constant $\mathrm{k}_{\mathrm{eff}}$, anharmonic parameters $\mathrm{k}_{3 \mathrm{eff}}$ for lattice crystals presented in terms of our calculated Morse potential parameters D and $\alpha$.

In the Eq. (25), $\sigma^{(\mathrm{n})}$ are cumulants, in which second cumulant $\sigma^{2}(\mathrm{~T})$ or Debye-Waller factor (DWF) or Mean Square Relative Displacement (MSRD) of the bond between two nearest atoms [6]. During the diffraction of neutrons or X-ray absorption, the DWF has a similar $\mathrm{u}^{2}(\mathrm{~T})$ form. In the EXAFS spectra, DWF is considered to correlated averages over the relative displacement of $\sigma^{2}(\mathrm{~T})$ for a pair of absorber and backscatter atoms. In comparison, neutron diffraction refers to the Mean Square Displacement $(\mathrm{MSD}) \mathrm{u}^{2}(\mathrm{~T})$ of a given atom. The functions $\sigma^{2}(\mathrm{~T})$ and $\mathrm{u}^{2}(\mathrm{~T})$ are closely related to one another. From them, the Displacement-Displacement Correlation Function $\mathrm{C}_{\mathrm{R}}(\mathrm{T})$ can be deduced to describe the correlation effects in the vibration of atoms. Based on anharmonic correlated Debye model, the expression for $\sigma^{2}(T)$ has the form [17]:

$$
\sigma^{2}(T)=\frac{\mathrm{h} a}{10 \pi \mathrm{D} \alpha^{2}} \int_{0}^{\pi / a} \omega_{A}(q) \frac{1+z_{A}(q)}{1-z_{A}(q)} d q,
$$




$$
z(q)=e^{-\left(\beta \mathrm{h} \omega_{A}(q)\right)}, \quad \omega_{A}(q)=2 \sqrt{\frac{10 \mathrm{D} \alpha^{2}}{M}}|\sin (q a / 2)|, \quad|q| \leq \pi / \mathrm{a} .
$$

Similarly, for the anharmonic Debye model, $\mathrm{u}^{2}(\mathrm{~T})$ have been determined as:

$$
\begin{gathered}
u^{2}(T)=\frac{\mathrm{h} a}{16 \pi \mathrm{D} \alpha^{2}} \int_{0}^{\pi / a} \omega_{D}(q) \frac{1+z_{D}(q)}{1-z_{D}(q)} d q \\
z_{D}(q)=e^{-\left(\beta \mathrm{h} \omega_{D}(q)\right)}, \quad \omega_{D}(q)=2 \sqrt{\frac{8 \mathrm{D} \alpha^{2}}{M}}|\sin (q a / 2)|, \quad|q| \leq \pi / \mathrm{a},
\end{gathered}
$$

where $a$ is the lattice constant, $\omega(\mathrm{q})$ and $q$ are the frequency and phonon wavenumber, $M$ is the mass of composite atoms.

\section{Numerical results and discussion}

To receive the Morse potential parameters, we need to calculate the parameter $\mathrm{c}$ in Eq. (10). The space lattice of the diamond is the fcc. The primordial basis has two identical atoms at $000,1 / 41 / 4$ $1 / 4$ connected with each point of the fcc lattice. Thus, the conventional unit cube contains eight atoms so that we obtain the value $\mathrm{c}=1 / 4$ for this structure.

Apply the above derived expressions, we calculate thermal parameters for DIA structure crystals ( $\mathrm{Si}, \mathrm{Ge}$ and $\mathrm{SiGe}$ ) using the energy of sublimation [10], the compressibility [14] and the lattice constants [11], as well as calculate for fcc structure crystals $\left(\mathrm{Cu}, \mathrm{Ag}\right.$, and $\mathrm{Cu}_{\mathrm{x}} \mathrm{Ag}_{\mathrm{y}}, \mathrm{x}=72,50 ; \mathrm{y}=$ 28,50).

The numerical results of the Morse potential parameters shown in Tables 1, 2, 5. The theory values of $\mathrm{D}, \alpha$ fit well with the measured experiment [10], [18-20]. The elastic constants $c_{i}$, effective spring force constants $k_{\text {eff }}$ and effective spring cubic parameters $k_{3 e f f}$ calculated by Morse potential parameters for $\mathrm{Si}, \mathrm{Ge}, \mathrm{Cu}, \mathrm{Ag}$ and their alloys are presented in Tables 3, 4 and compared to the experimental values [11], [18-20]. Table 5 shown Morse potential parameters, spring force constants and cubic parameters under pressure effects for $\mathrm{Cu}_{50} \mathrm{Ag}_{50}$ up to $14 \mathrm{GPa}$.

Table 1: Morse potential parameters D, $\alpha$ and the related parameter ro of Si, Ge and SiGe in comparison to some experimental results [10].

\begin{tabular}{ccccc}
\hline Crystal & $\beta$ & $\alpha\left(\AA^{-1}\right)$ & $\mathrm{D}(\mathrm{eV})$ & $r_{0}(\AA)$ \\
\hline Si (Present) & 120.110 & 1.3642 & 0.9862 & 2.8429 \\
Si (Expt.) & - & 1.3106 & - & 2.7503 \\
Ge (Present) & 327.210 & 1.5569 & 0.9675 & 2.8319 \\
Ge (Expt.) & - & 1.4105 & - & 2.7442 \\
SiGe (Present) & - & 1.4606 & 0.9769 & 2.7934 \\
\hline
\end{tabular}

Table 2. Parameters $D$ and $\alpha$ for Morse potential for $\mathrm{Cu}, \mathrm{Ag}$ and CuAg in comparison to some experimental results for $\mathrm{Cu}, \mathrm{Ag}$ [18-20]. 


\begin{tabular}{ccccc}
\hline $\begin{array}{c}\text { Quantity/ } \\
\text { Crystal }\end{array}$ & $\begin{array}{c}\mathrm{D}[\mathrm{eV}] \\
\text { (Present) }\end{array}$ & $\begin{array}{c}\mathrm{D}[\mathrm{eV}] \\
(\text { Exp. })\end{array}$ & $\begin{array}{c}\alpha\left[\AA^{-1}\right] \\
(\text { Present })\end{array}$ & $\begin{array}{c}\alpha\left[\AA^{-1}\right] \\
(\text { Expt. })\end{array}$ \\
\hline $\mathrm{Cu}-\mathrm{Cu}$ & 0.3429 & 0.3528 & 1.3588 & 1.4072 \\
$\mathrm{Ag}-\mathrm{Ag}$ & 0.3323 & 0.3253 & 1.3690 & 1.3535 \\
$\mathrm{Cu}_{72} \mathrm{Ag}_{28}$ & 0.3381 & - & 1.3634 & - \\
$\mathrm{Cu}_{50} \mathrm{Ag}_{50}$ & 0.3376 & - & 1.3638 & - \\
\hline
\end{tabular}

Table 3: Values elastic constants $\left(x 10^{-11} \mathrm{~N} / \mathrm{m}\right)$ for Si, Ge by present theory and experimental values [11].

\begin{tabular}{ccccc}
\hline Crystal & $\mathrm{c}_{11}$ & $\mathrm{c}_{12}$ & $\mathrm{c}_{13}$ & $\mathrm{c}_{33}$ \\
\hline $\mathrm{Si}$ (Present) & 1.85 & 0.64 & 0.55 & 2.13 \\
$\mathrm{Si}$ (Expt.) & 1.77 & 0.41 & 0.61 & 1.54 \\
$\mathrm{Ge}$ (Present) & 1.46 & 0.57 & 0.46 & 1.63 \\
$\mathrm{Ge}$ (Expt.) & 1.35 & 0.52 & 0.52 & 0.57 \\
\hline
\end{tabular}

Table 4. Effective spring force constants and cubic parameters for $\mathrm{Cu}, \mathrm{Ag}$, CuAg by present theory and experimental values of $\mathrm{Cu}, \mathrm{Ag}$ [18-20].

\begin{tabular}{ccccc}
\hline $\begin{array}{c}\text { Quantity/ } \\
\text { Crystal }\end{array}$ & $\begin{array}{c}\mathrm{k}_{\text {eff }}\left[\mathrm{eV} / \AA^{2}\right] \\
(\text { Present })\end{array}$ & $\begin{array}{c}\mathrm{k}_{\text {eff }}\left[\mathrm{eV} / \AA^{2}\right] \\
(\text { Exp. })\end{array}$ & $\begin{array}{c}\mathrm{k}_{3 \text { eff }}\left[\mathrm{eV} / \AA^{3}\right] \\
(\text { Present })\end{array}$ & $\begin{array}{c}\mathrm{k}_{3 \text { eff }}\left[\mathrm{eV} / \AA^{3}\right] \\
(\text { Exp. })\end{array}$ \\
\hline $\mathrm{Cu}-\mathrm{Cu}$ & 3.1655 & 3.4931 & 3.0889 & 2.9831 \\
$\mathrm{Ag}-\mathrm{Ag}$ & 3.1139 & 2.9797 & 3.4674 & 3.0563 \\
$\mathrm{Cu}_{72} \mathrm{Ag} \mathrm{g}_{28}$ & 3.1423 & - & 2.6874 & - \\
$\mathrm{Cu}_{50} \mathrm{Agg}_{50}$ & 3.1396 & - & 0.8569 & - \\
\hline
\end{tabular}

Table 5. Morse potential parameters, spring force constants and cubic parameters under pressure effects for $\mathrm{Cu}_{50} \mathrm{Ag}_{50}$ up to $14 \mathrm{GPa}$

\begin{tabular}{ccccc}
\hline Pressure $(\mathrm{GPa})$ & $\mathrm{D}(\mathrm{eV})$ & $\alpha\left(\AA^{-1}\right)$ & $\mathrm{k}_{\text {eff }}\left(\mathrm{eV} / \AA^{2}\right)$ & $\mathrm{k}_{\text {3eff }}\left(\mathrm{eV} / \AA^{3}\right)$ \\
\hline 0 & 0.3376 & 1.3588 & 3.1396 & 0.6423 \\
5 & 0.3154 & 1.3485 & 2.9032 & 0.6415 \\
10 & 0.2977 & 1.3168 & 2.7428 & 0.5902 \\
14 & 0.2184 & 1.2854 & 2.3595 & 0.5527 \\
\hline
\end{tabular}

The computed results for the state equation illustrated in Figure 1 for Si crystal, Figure 2 for Ge crystal, and compared with the experimental ones (dashed line) [10] represented by an 
extrapolation procedure of the measured data, the graphs shown they agree well, especially at low pressure.

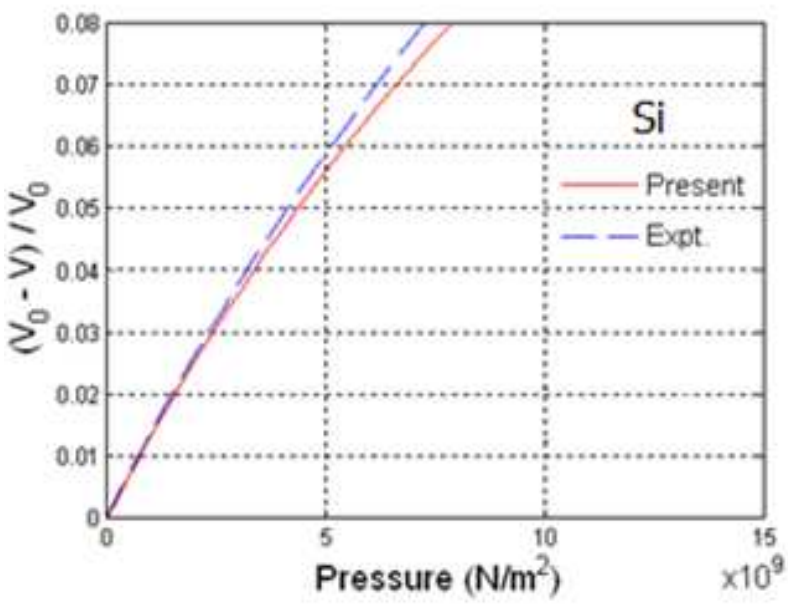

Figure 1. State equation for $\mathrm{Si}$

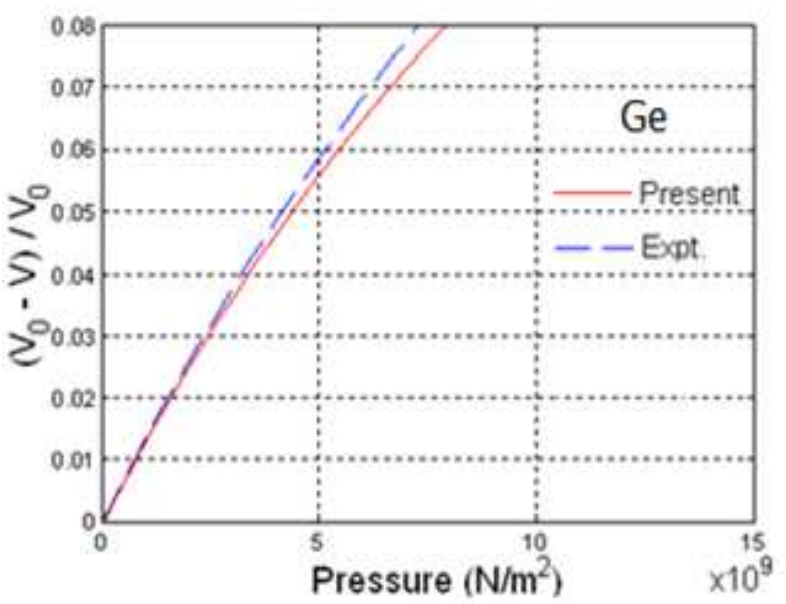

Figure 2. State equation for Ge

Figures 3 and 4 illustrate good agreement of the anharmonic interatomic effective potentials for $\mathrm{Si}, \mathrm{Ge}$ and $\mathrm{SiGe}$ semiconductor calculated using the present theory (solid line), and the experiment values obtained from Morse potential parameters of J. C. Slater (solid line and symbol $\square$ ) [10], and simultaneously shows strong asymmetry of these potentials due to the anharmonic contributions in atomic vibrations of these DIA structure crystals illustrate by their anharmonic shifting from the harmonic terms (dashed line).

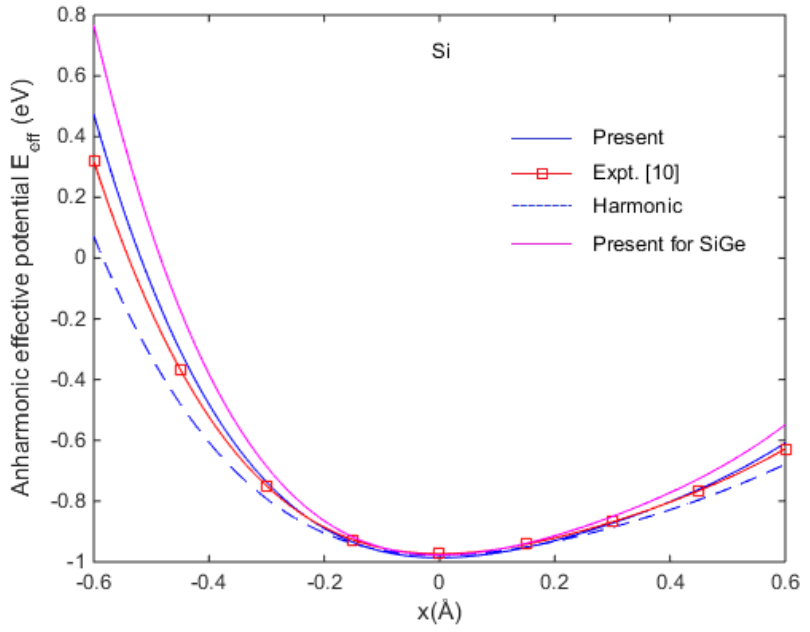

Figure 3. Anharmonic effective potential for $\mathrm{Si}$, and $\mathrm{SiGe}$ semiconductor

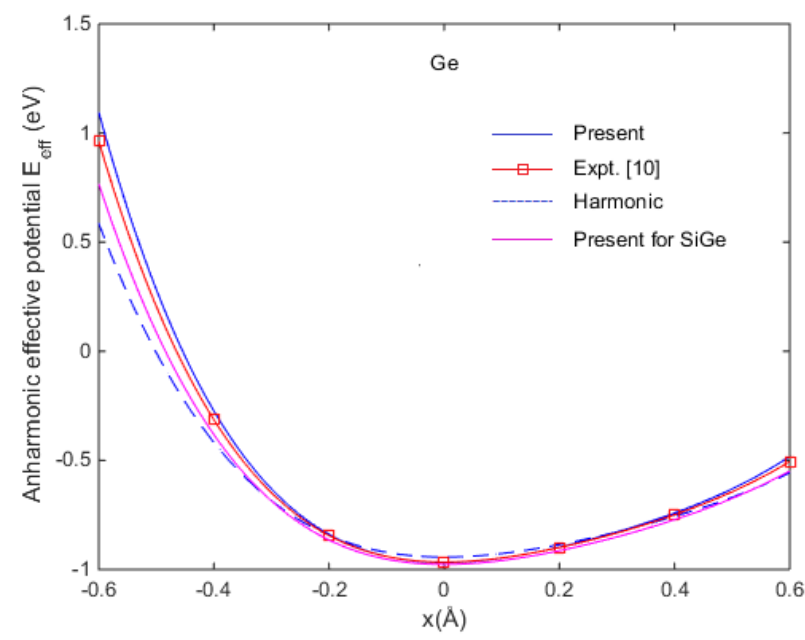

Figure 4. Anharmonic effective potential for Ge, and $\mathrm{SiGe}$ semiconductor

Figures 5, 6 showns the temperature and pressure dependence of mean square relative displacement $\sigma 2(\mathrm{~T})$ and mean square displacement $\mathrm{u} 2(\mathrm{~T})$ for $\mathrm{Si}$ and Ge crystals. They show linear proportional to the temperature $\mathrm{T}$ at high temperatures, and the classical limit is applicable. At low temperatures, the curves for $\mathrm{Si}$ and Ge contain zero-point energy contributions - a 
quantum effect. Simultaneously, the values of $\sigma 2(\mathrm{~T})$ are greater than the values of $u 2(T)$. The calculated results of $\sigma 2(\mathrm{~T}), \mathrm{u} 2(\mathrm{~T})$ for the $\mathrm{Si}$, Ge crystals fitting well with the experimental values [10]. Thus, it is possible to deduce that the calculation results of the present method for diamond structure crystals such as $\mathrm{Si}, \mathrm{Ge}$ crystals are reasonable.

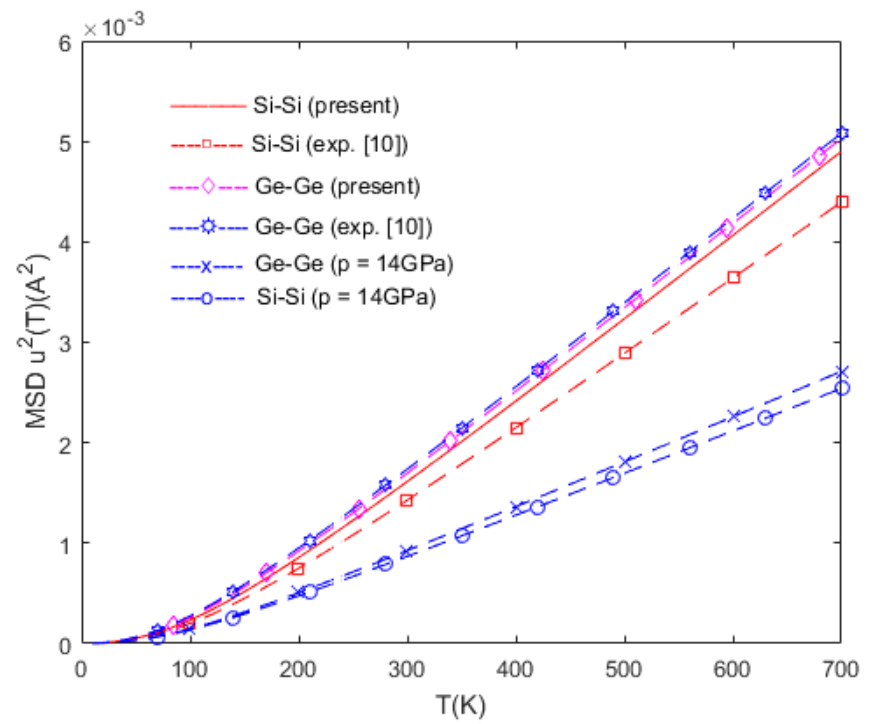

Figure 5. Mean square displacement dependence on temperature and under pressure effects up to $14 \mathrm{GPa}$

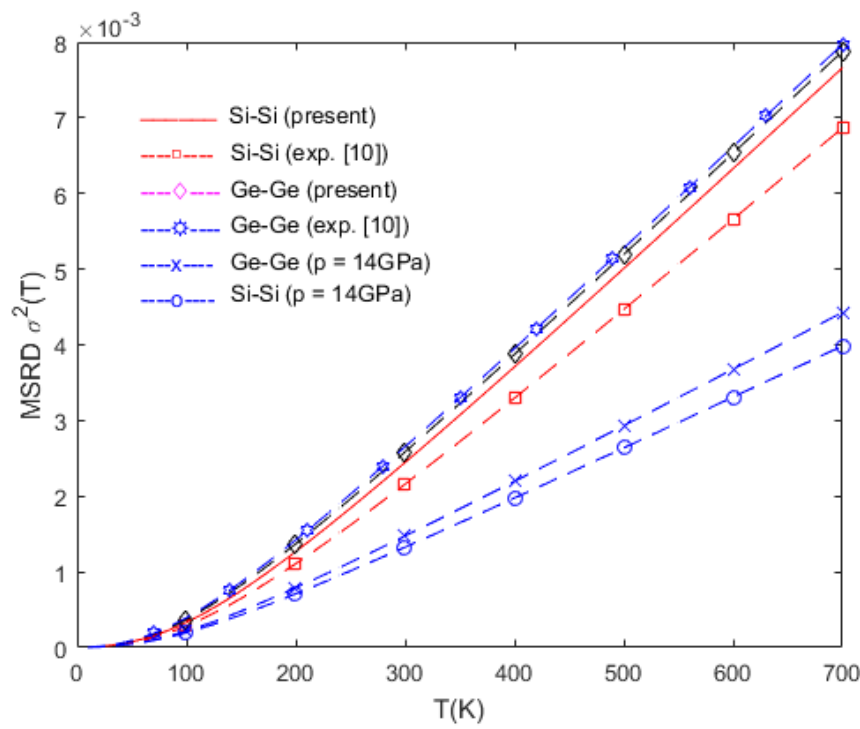

Figure 6. Mean square relative displacement dependence on temperature and under pressure effects up to $14 \mathrm{GPa}$

Figure 7 shows how $\mathrm{C}_{\mathrm{R}}(\mathrm{T})$ depends on temperature for $\mathrm{Cu}, \mathrm{Ag}$ and $\mathrm{Cu}_{\mathrm{x}} \mathrm{Ag}_{\mathrm{y}}$ under pressure effects up to $14 \mathrm{GPa}$. Similar to Figures 4 and 5 , each correlation function is linearly proportional to $\mathrm{T}$ at high temperatures, and the classical limit is applicable. At low temperatures, the curves for $\mathrm{Cu}$, $\mathrm{Ag}$ and $\mathrm{Cu}_{\mathrm{x}} \mathrm{Ag}_{\mathrm{y}}(\mathrm{x}=72,50, \mathrm{y}=28,50)$ contain zero-point energy contributions, which is a quantum 
effect. The calculated results of $\sigma^{2}(\mathrm{~T}), \mathrm{u}^{2}(\mathrm{~T})$ for $\mathrm{Si}, \mathrm{Ge}$, and $\mathrm{C}_{\mathrm{R}}(\mathrm{T})$ for $\mathrm{Cu}, \mathrm{Ag}$ fit well with the experimental values [10], [18], [19], [20], and those for $\mathrm{Cu}_{\mathrm{x}} \mathrm{Ag}_{\mathrm{y}}(\mathrm{x}=72,50, \mathrm{y}=28,50)$ agree well with other theories [17]. Thus, it is possible to deduce that the calculation results of the present method for Morse potential parameters are reasonable.

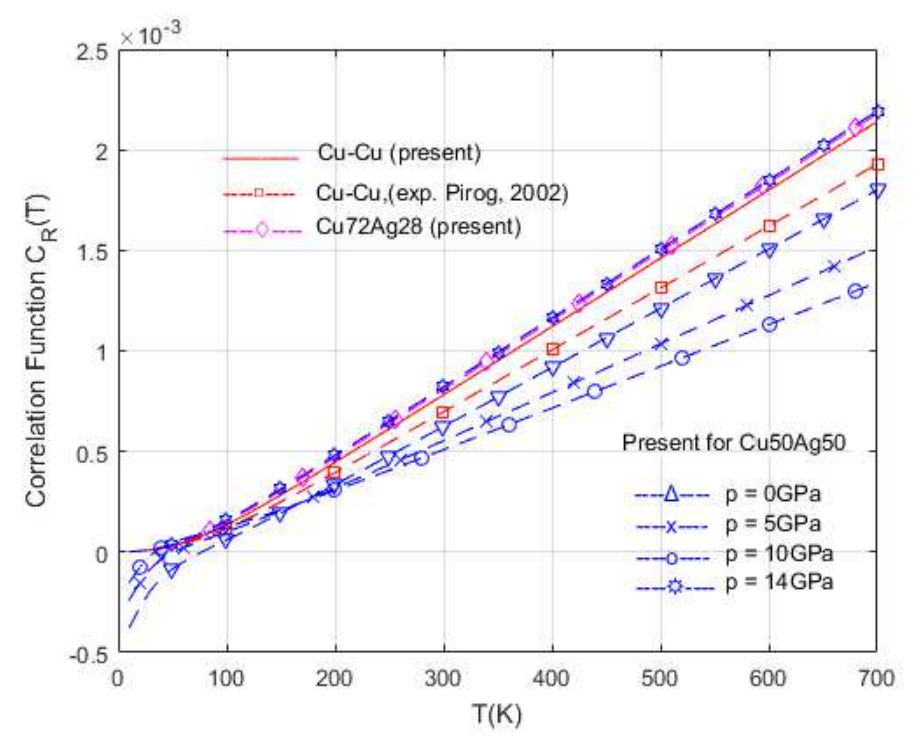

Figure 7. Correlation function dependence on temperature under pressure up to $14 \mathrm{GPa}$

\section{Conclusions}

In this work, a calculation method of Morse potential parameters and application for DIA and fcc structure crystals have been developed based on the calculation of volume and number of an atom in each basic cell and the sublimation energy, compressibility, and lattice constant. The results have applied to the mean square relative displacement, mean square displacement, the state equation, the elastic constants, anharmonic interatomic effective potential, correlated function and local force constant in EXAFS theory.

Derived equation of state and elastic constants satisfy all standard conditions for these values, for example, all elastic constants are positive. The Morse potentials obtained satisfy all their basic properties. They are reasonable for calculating and analyzing the anharmonic interatomic effective potentials describing anharmonic effects in EXAFS theory. This procedure can be generalized to the other crystal structures based on calculating their volume and number of an atom in each elementary cell.

Reasonable agreement between our calculated results and the experimental data show the efficiency of the present procedure. The calculation of potential atomic parameters is essential for estimating and analyzing physical effects in the EXAFS technique. It can solve the problems involving any deformation and of atom interaction in the diamond structure crystals. 


\section{Acknowledgement}

One of the authors (N. B. Duc) thanks the Tan Trao University, Tuyen Quang, Viet Nam for support.

\section{Data availability}

The datasets generated and analysed during the current study are available from the corresponding author upon reasonable request.

\section{References}

[1] Marques, E. C., Sandrom, D. R., Lytle, F. W. \& Greegor, R. B. Determination of thermal amplitude of surface atoms in a supported Pt catalyst by EXAFS spectroscopy. J. Chem. Phys. 77, 1027(1982).

[2] Duc, N. B., Binh, N. T. Statistical Physics-Theory and Application in XAFS, 173-198 (LAP LAMBERT, Academic Publishing, 2017).

[3] Hung, N. V., Duc, N. B. \& Frahm, R. R. A New Anharmonic Factor and EXAFS Including Anharmonic Contributions. J. Phys. Soc. Jpn. 72(5), 1254 (2002).

[4] Frenkel, A. I., Rehr, J. J. Thermal expansion and x-ray-absorption fine-structure cumulants. Phys. Rev. B, 48, 585 (1993).

[5] Miyanaga, T. and Fujikawa, T. Quantum Statistical Approach to Debye-Waller Factor in EXAFS, EELS and ARXPS. III. Applicability of Debye and Einstein Approximation. J. Phys. Soc. Jpn. 631036 (1994).

[6] Hung, N. V., Rehr, J. J., Anharmonic correlated Einstein-model Debye-Waller factors. Phys. Rev. B 56, 43 (1997).

[7] Miyanaga, T., Katsumata, H., Fujikawa, T., \& Ohta, T. Ab Initio Calculations of EXAFS Debye-Waller Factors for Two- and Three-Dimensional Crystals. J. de Physique. IV, C2: 225173 (1997).

[8] Girifalco, L. A. and Weizer, V. G. Application of the Morse Potential Function to Cubic Metals. Phys. Rev. 114, 687 (1959).

[9] Pirog, I. V., Nedoseikina, T. I., Zarubin, A. I., Shuvaev, A. T. Anharmonic pair potential study in face-centred-cubic structure metals. J. Phys.: Condens. Matter 14, 1825. (2002).

[10] Slater, J. C.. Introduction to Chemical Physics, (ed. McGraw) (Hill Book Company, Inc., New York, 1939).

[11] Sydney,P., Clark, J. Handbook of Physical Constants (Geological Society of America 1996).

[12] Charles Kittel, Introduction to Solid-State Physics, (John Wiley \& Sons ed.), (Inc. New York, 1986). 
[13] M. Born, K. Huang. Dynamical Theory of Crystal Lattice, $2^{\text {nd }}$ Ed., (Oxford: Clarendon Press. 1956).

[14] Bridgeman, P. W. The Compression of 46 Substances to $50,000 \mathrm{~kg} / \mathrm{cm}$. Proceedings of the American Academy of Arts and Sciences, 74, 3, 21-51(1940).

[15] Fowler, R. H., Guggenheim, E. A. Statistical Thermodynamics: a version of statistical mechanics for students of physics and chemistry (Cambridge University Press, 1939).

[16] Mott, N., Jones, H. Properties of Metals and Alloys (Oxford Uni. Press, London, 1936).

[17] Duc, N. B. Application of the Debye model to study anharmonic correlation effects for the $\mathrm{CuAgX}(\mathrm{X}=72 ; 50)$ intermetallic alloy, Physica Scripta, 95 (2020).

[18] Greegor, R. B. and Lytle F. W. Extended x-ray absorption fine structure determination of thermal disorder in $\mathrm{Cu}$ : Comparison of theory and experiment. Phys. Rev. B 20, 4908. (1979).

[19] Okube, M. and Yoshiasa, A. Anharmonic Effective Pair Potentials of Group VIII and Lb Fcc Metals. J. Synchrotron Radiat. 8, 937 (2001).

[20] Yokoyama, T., Sasukawa, T. and Ohta T. Anharmonic Interatomic Potentials of Metals and Metal Bromides Determined by EXAFS. Jpn. J. Appl. Phys. 28, 1905(1989).

\section{Contributions}

N. B. D analyzed the structural data, conceptualized and wrote the manuscript, T. P. H supported the data analysis, N. V. T edited the manuscript. All authors reviewed the manuscript.

\section{Corresponding author}

Correspondence to Nguyen Ba Duc

\section{Conflicts of Interest}

The authors declare that they have no conflicts of interest. 
Figures



Figure 1

State equation for $\mathrm{Si}$ 


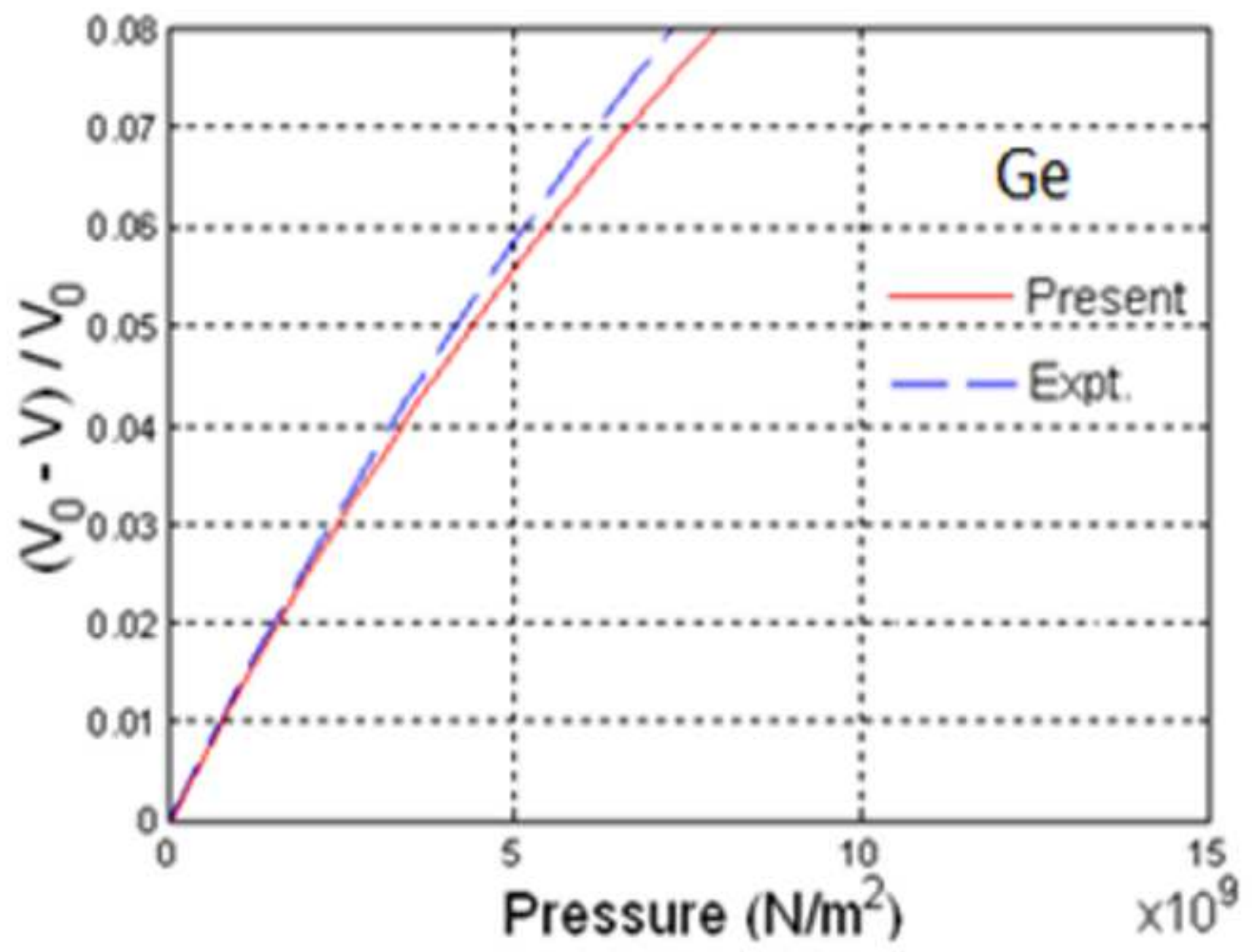

Figure 2

State equation for $\mathrm{Ge}$ 


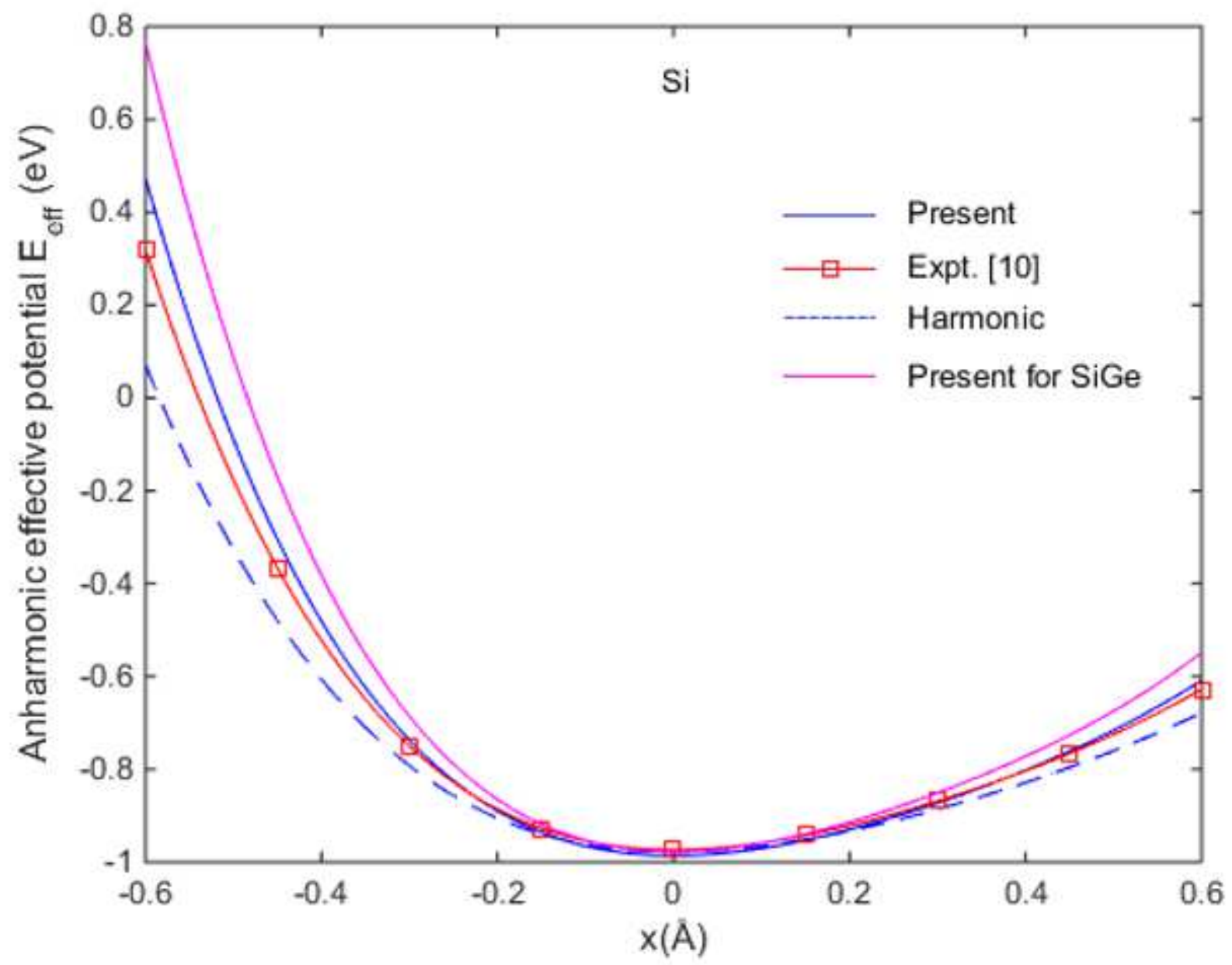

Figure 3

Anharmonic effective potential for Si and SiGe semiconductor 


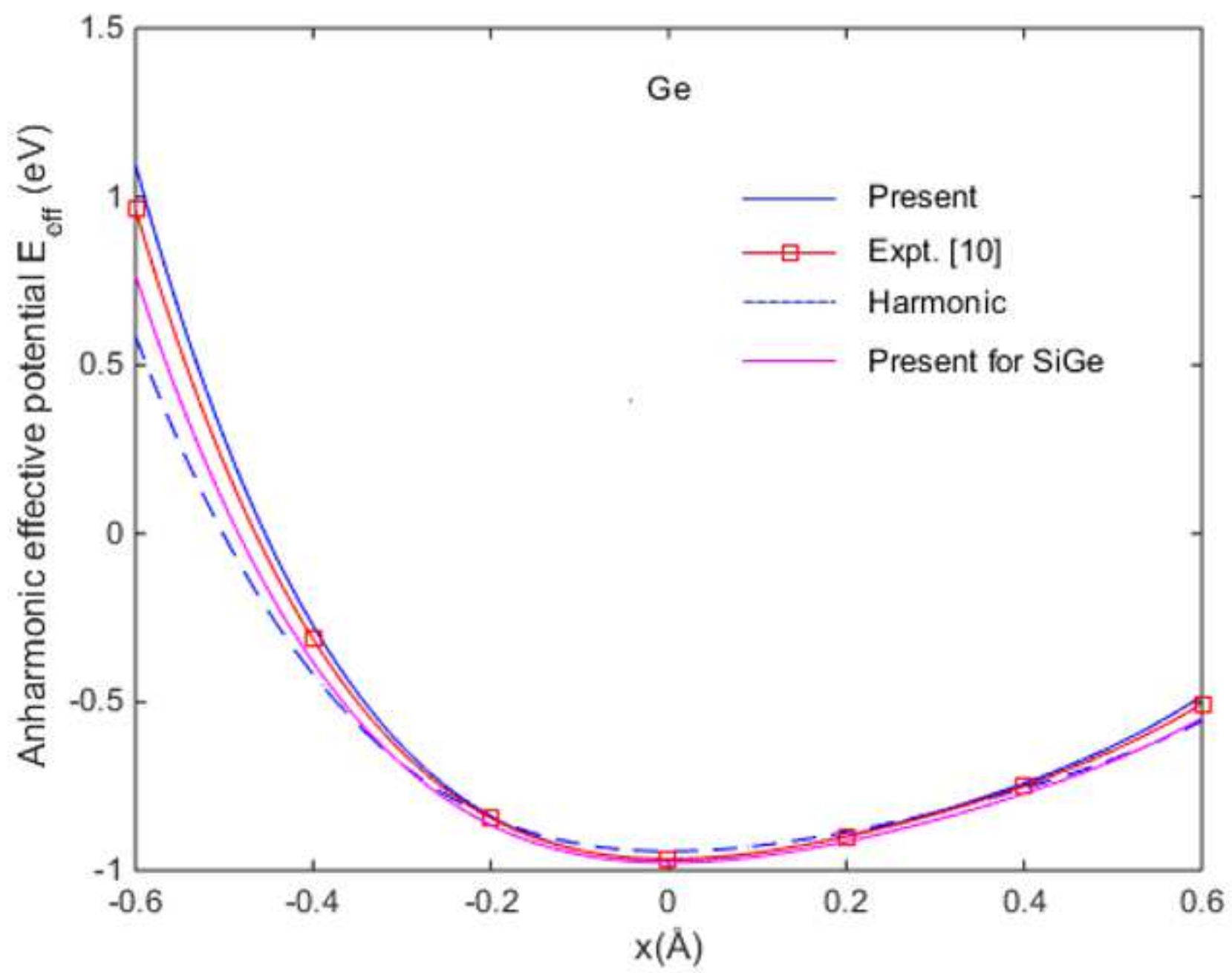

Figure 4

Anharmonic effective potential for $\mathrm{Ge}$ and SiGe semiconductor 


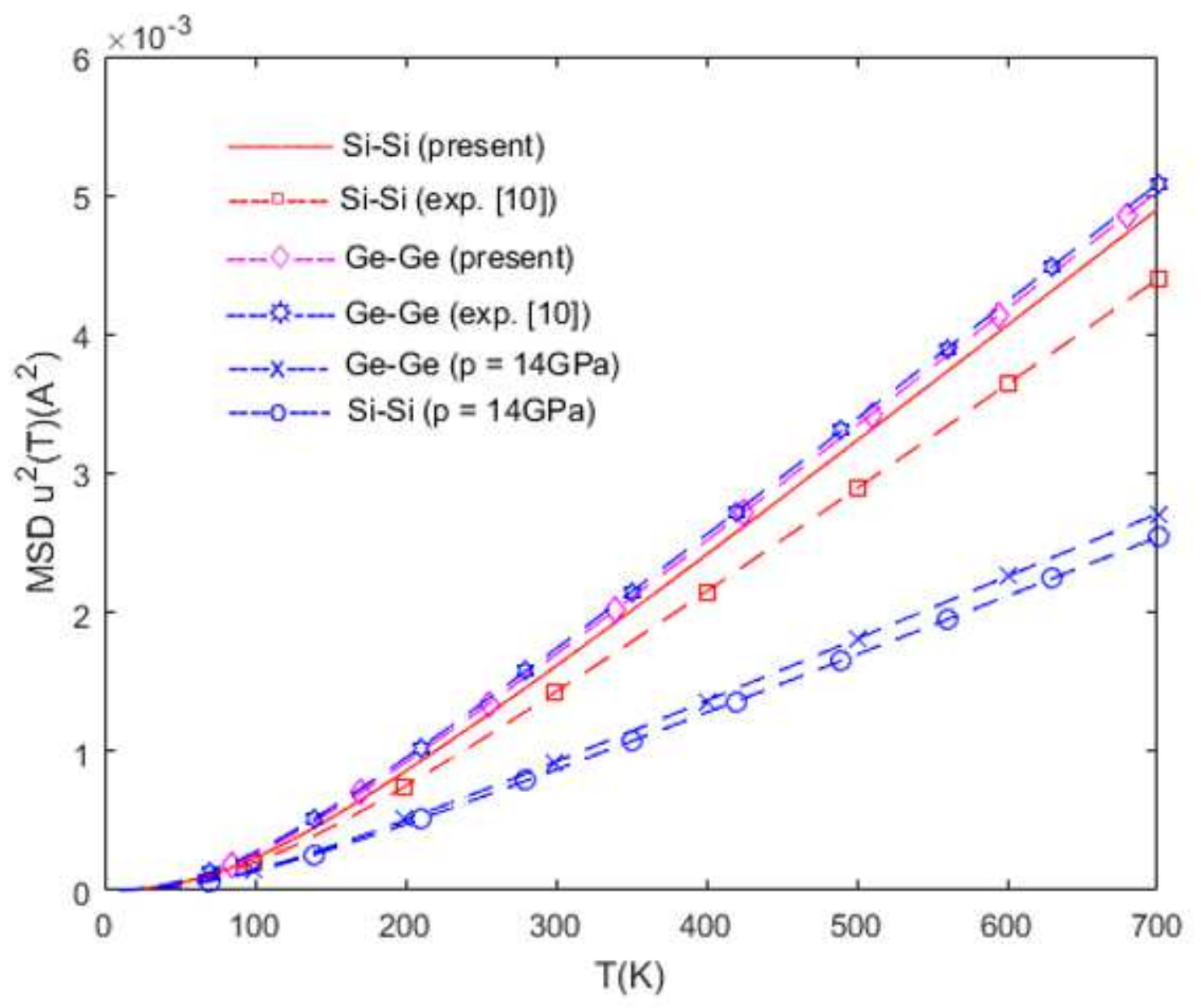

Figure 5

Mean square displacement dependence on temperature and under pressure effects up to $14 \mathrm{GPa}$ 


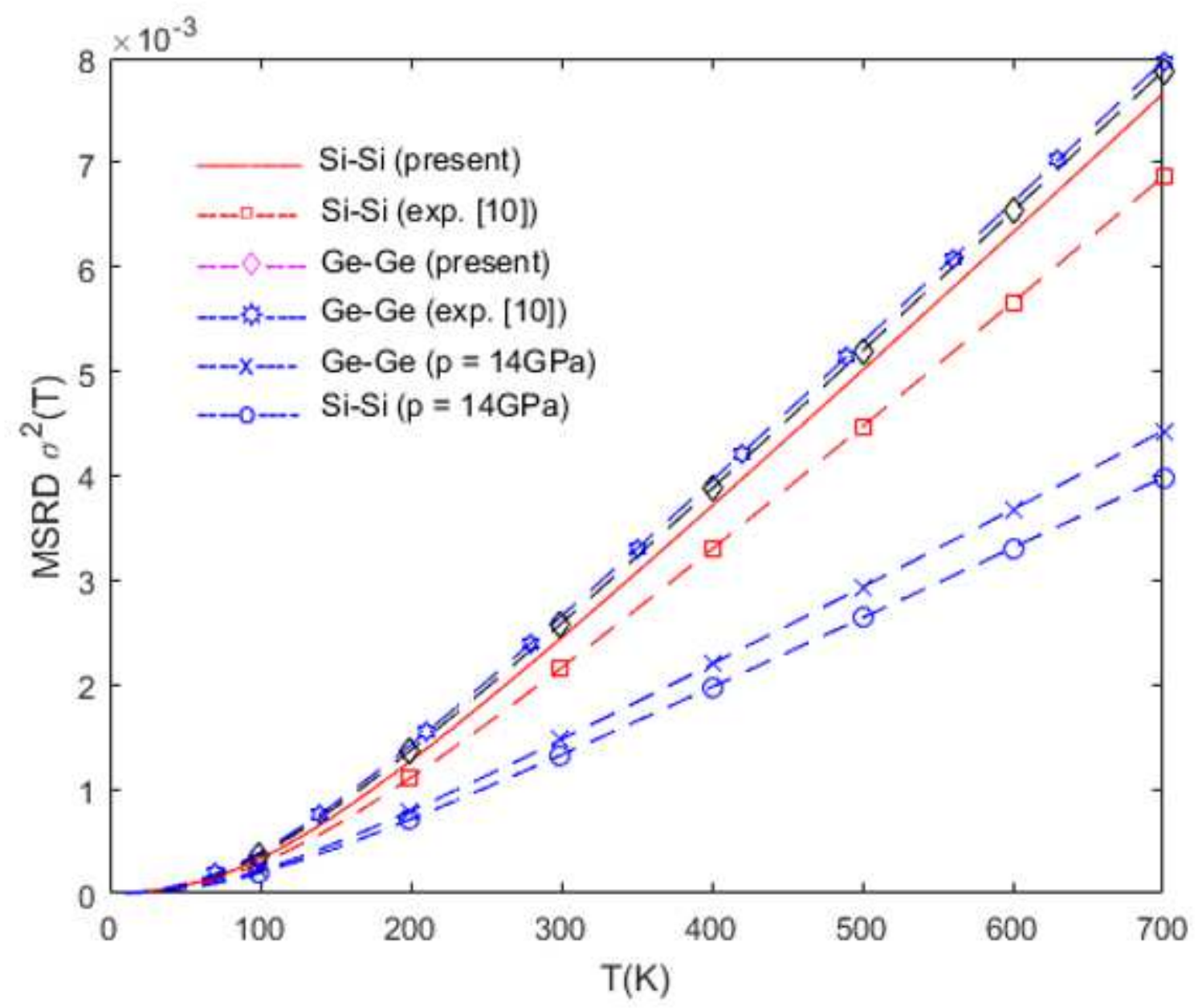

Figure 6

Mean square relative displacement dependence on temperature and under pressure effects up to 14GPa 




Figure 7

Correlation function dependence on temperature under pressure up to $14 \mathrm{GPa}$ 